\title{
TRANS/IDENTIDADES: LITERATURA, CINEMA E OUTRAS ARTES EM PERSPECTIVA COMPARADA
}

\author{
Anselmo Peres Alós ${ }^{1}$ \\ Amara Moira ${ }^{2}$ \\ Adauto Locatelli TAUfFer ${ }^{3}$ \\ ${ }^{1}$ Universidade Federal de Santa Maria. Santa Maria, RS, Brasil. \\ E-mail: anselmoperesalos@gmail.com \\ ${ }^{2}$ Universidade Estadual de Campinas. Campinas, SP, Brasil. \\ E-mail: amoiramara@gmail.com \\ ${ }^{3}$ Universidade Federal do Rio Grande do Sul. Porto Alegre, RS, Brasil. \\ E-mail: adautotaufer@gmail.com
}

EDITOR-CHEFE:

Gerson Roberto Neumann

EDITOR EXECUTIVO:

Regina Zilberman

SUBMETIDO: 30.04 .2021

ACEITO: 15.06 .2021

COMO CITAR:

ALÓS, Anselmo Peres; MOIRA, Amara; TAUFFER, Adauto Locatelli. Trans/ identidades: literatura, cinema e outras artes em perspectiva comparada. Revista Brasileira de Literatura Comparada, v. 23, n. 44, p. 5-8, set.-dez., 2021. doi: https:// doi.org/10.1590/2596$304 \times 20212344$ aaamat

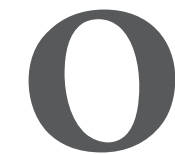
jovem século XXI inicia-se com uma abertura sem precedentes para a discussão de gênero, raça/etnia, classe e sexualidade, seja na academia, seja nos movimentos sociais. Veja-se, a título de exemplo, trabalhos como os de Susan Stryker (Transgender History: the roots of today's revolution, 2017), Sally Hines (TransForming Gender, 2007), Judith Halberstam (In a a Queer Time and Place: transgender bodies, subcultural lives, 2005) e Aren Z. Aizura (Mobile Subjects: transnational imaginaries of gender reassignment, 2018). Nesse cenário, a emersão do ativismo, do pensamento e da autoria trans surge como um lugar epistêmico privilegiado para se pensar/problematizar tanto os regimes de representação quanto a autoria trans (termo aglutinador para as identidades travesti, transexual, transgênera, e não binária e, muitas vezes, também para a identidade intersexual). Os estudos de literatura comparada não estiveram alheios à crítica feminista, aos estudos gays e lésbicos e aos influxos da teoria queer, e vêm mostrando hospitalidade às discussões de como o campo da cultura tem lidado com as transformações e subversões da gramática simbólica (gramática essa que ainda hoje se mostra acumpliciada a regimes hetero-e cisnormativos no que tange aos campos de produção e de circulação de capital cultural). Como diferentes discursos artísticos têm representado as identidades trans ao longo da história? Como artistas e escritoras/ es trans têm feito dos discursos artísticos e literários loci privilegiados para a contestação das normas de gênero e de sexualidade? Que tipo de coalizão pode emergir do encontro das discussões do pensamento trans com outros campos, como os estudos de classe, raça e etnia? Que travessias 
teóricas, temáticas e conceituais emergem quando o pensamento trans encontra-se/confronta-se com os feminismos, os estudos de gênero e a teoria queer? Essas são algumas das perguntas norteadoras que, a título de provocação, nortearam a construção deste número temático da Revista brasileira de literatura comparada.

O queer é substantivo, verbo e adjetivo. O queer é radicalmente diferente das políticas identitárias que se ocultam por trás das siglas como GLS ${ }^{1}, \mathrm{LGBT}^{2}, \mathrm{LGBTT}^{3}$ ou LGBTTTQIA $+{ }^{4}$. Mesmo quando se tenta subsumir o queer em uma sigla, o queer escorre, como areia pelos dedos, das tentativas de fixação e cristalização identitárias. O queer é liquidez, é fluxo, movimento, errância e metamorfose permanente. É processo sem telos. É avesso às políticas de representatividade, pois o que questiona é justamente a fixidez essencialista, normativa e colonial dos regimes de representação enquadrados no frame cis/heteronormativo. O queer é uma postura que vem das ruas, de muitas e diferentes ruas, em diferentes temporalidades, em diferentes geografias e latitudes. O queer é poliglota, e seu discurso é marcado pela heteroglossia. O queer fala diferentes línguas, e tem diferentes nomes. O queer é um gesto de posicionamento contra; é uma política (talvez várias, complementares e não raro em explícita condição de disputa pela significação); o queer é uma epistemologia (talvez, mais de uma); o queer é uma estratégia de ação e de resistência aos abusos heteronormativos e ao Terror de Estado heterossexual. Se o levante do Stonewall Inn, em 28 de junho de 1969, foi considerado o momento fundador da resistência queer, não custa refrescar nossa memória política e chamar a atenção para o fato de que foram as transexuais, as travestis e as drag queens que estiveram na linha de frente do embate com a polícia repressora ao longo daquela madrugada que entraria para a história. Elas literalmente desceram dos saltos para partir para a luta.

Como resposta ao conjunto de provocações que enunciamos por ocasião da proposta do presente número temático da $R B L C$, recebemos um conjunto importante de colaborações na forma de artigos. Nesse conjunto de escritos, podem ser observadas duas tendências recorrentes: na primeira delas, o que se observa é a interpretação da figuração transexual em diferentes artefatos culturais (textos literários, fílmicos e televisivos); na segunda delas, a preocupação é invocar o deslocamento das pessoas transexuais e transgêneras da condição de objeto à condição de sujeito da representação cultural, privilegiando a superposição da condição transexual à condição de autoria e produção de artefatos culturais. Esse conjunto de artigos, todos inéditos, configura a primeira parte desse número da $R B L C$.

Mário César Lugarinho e Helder Thiago Maia revisitam o romance A Senhora de Pangim, do autor integralista brasileiro Gustavo Barroso, publicado, no Brasil, em 1932, e, em Portugal em 1940, analisando representações gráficas da personagem histórica de Baltasar do Couto Cardoso/Maria Úrsula de Abreu e Lencastro (1682-1730), de modo a interpretar as reiterações e rupturas entre o discurso histórico e o discurso literário, com foco na discussão sobre donzelas-guerreiras e a maneira como essas representações consideraram a instabilidade de gênero da personagem. Émerson da Cruz Inácio, por sua vez, estabelece uma leitura comparativa de Fluxo-Floema, de Hilda Hilst, e de Novas Cartas Portuguesas, de Maria Isabel Barreno, Maria Velho da Costa e Maria Teresa Horta, pensando

\footnotetext{
1 Gays, lésbicas e simpatizantes.

2 Lésbicas, gays, bissexuais e travestis.

3 Lésbicas, gays, bissexuais, travestis, transexuais e transgêneros.

4 Lésbicas, gays, bissexuais, travestis, transexuais, transgêneros, queers, intersexuais, assexuais e outros mais.
} 
as homologias, analogias e amálgamas existentes entre os gêneros literários e os gêneros sexuais/ identitários. Rafael Magno analisa o conto “Marieta e Ferdinando” (de Sérgio Sant’Anna), investigando a composição dos estereótipos masculino e feminino como produtos de condições sociais que determinam certas práticas, verificando como a luta constante pelo exercício da sexualidade e pela manutenção da juventude do corpo são fatores que desvelam a artificialidade de determinados padrões de gênero como algo socialmente construído.

Partindo da ideia da corporeidade transgênero como metáfora para se compreender as diversas possibilidades de transgeneridade, Emerson Silvestre explora como a personagem transgênera tem sido representada em narrativas literárias brasileiras. Para tanto, faz-se necessário comparar o modelo representacional de autores cisgêneros com a representação empreendida por autores e autoras transgêneros. Nessa empreitada, é importante encarar os textos de autoria trans a partir de uma visada transfeminista, isto é, de um escopo teórico criador por, e destinado às próprias pessoas trans. Nesse mesmo caminho segue Anselmo Peres Alós, que mapeia a tradição da representação de personagens transgêneros - especialmente protagonistas - na narrativa brasileira escrita por autores transgêneros; por outro, discute-se a emergência do fenômeno que pode ser chamado de autoria transgênero no campo da narrativa contemporânea brasileira, dando-se especial atenção aos livros escritos por João Nery (Erro de pessoa, de 1985, e Viagem solitária, de 2011) e Loris Ádreon (Meu corpo, minha prisão, de 1985). Também nessa esteira, pode-se mencionar o artigo de Leocádia Aparecida Chaves, que se ocupa com as autobiografias de autoria trans no Brasil, publicadas entre 1998 e 2008, as quais, na abordagem proposta, vêm à tona como enunciações rebeldes em relação ao status apresentado, seja pelo sucesso profissional, no caso de Ruddy Pinho (1998, 2007), seja pelo ativismo, como ocorre com a obra de Claudia Wonder (2008).

Ruan Nunes Silva busca oferecer uma compreensão do corpo como um arquivo ao analisar poemas escritos por Danez Smith, poeta e performer queer não binárie. Visto como um campo conflitante por disputas de poder e controle, o arquivo pode ser lido de diversas formas e este trabalho se aproxima dele para teorizar o que práticas arquivistas queer podem sinalizar quando elementos como gênero, sexualidade e desejo são interrogadas nos poemas de Smith. Sérgio Rodrigo da Silva Ferreira discute o processo de se afirmar como sujeito transgênero tendo em vista as possibilidades tecnológicas (médicas, de escrita, de comunicação) e normativas de cada período histórico e cultural; para tanto, discute o atravessamento das tecnologias na ação de dizer-a-verdade-sobre-si de sujeitos trans e a influência da normatividade de gênero nos regimes de verdade. Andrio R. J. dos Santos, por sua vez, realiza uma leitura de The Lazarus Heart, do autor trans PoppyZ. Brite. Em seu artigo, Santos discute como corpo, gênero e sexualidade ocupam papel central na obra de Brite, o que permite que sua obra seja lida a partir do escopo do gótico queer, um interstício entre os estudos do gótico e os estudos queer. Maria Clara da Silva Ramos Carneiro analisa a obra de Laerte Coutinho. Hoje assumidamente uma pessoa transgênero, Coutinho tem cerca de 50 anos de carreira e uma obra vasta no formato fragmentário de tiras e histórias curtas em quadrinhos.

Régis Abud Filho dedica atenção ao romance de Han Ryner, La Fille manquée (1903), buscando questionar a complexidade da natureza e da sexualidade humanas. Para tanto, Abud Filho recorre aos discursos científicos do século XIX e a alguns estudos de Freud, considerando a estrutura do romance, a construção da personagem e o contexto literário da época. Natália Salomé Poubel e Vinícius Carvalho 
Pereira discutem a obra da escritora estadunidense Joy Ladin, mulher trans, judia, poetisa premiada e professora universitária, em cuja escrita observamos uma constante reelaboração do performar-se mulher, num continuum feminino. Nessa discussão, Poubel e Pereira entendem a escrita como espaço para acolher e expressar identidades que não são estáveis e nem semelhantes, demonstrando como as performances das eu líricas na poesia de Joy Ladin podem moldar variadas mulheres. Djalma Thürller debruça-se sobre o texto de teatro And Tell Sad Stories of the Deaths of Queens, de Tennessee Williams, e procura demonstrar a consciência do autor sobre o camp e intenta discutir a tradução da expressão queen e suas implicações no casting da personagem Candy na cena contemporânea.

A segunda parte do presente número da $R B L C$ é composta por um artigo pela primeira vez traduzido ao português, por duas entrevistas e por três resenhas. "La mirada queer ante la violencia en tres casos de performance mexicano", de autoria de professor Hector Domínguez-Huvalcaba, docente e pesquisador na University of Texas at Austin, foi originalmente publicado em espanhol na revista El lugar sin límites, em 2021, e aparece aqui pela primeira vez traduzido para o português. Hector Domínguez-Huvalcaba gentilmente também nos concedeu uma entrevista, na qual fala de sua trajetória acadêmica e da pesquisa produzida na interface da teoria queer com o latino-americanismo. A segunda entrevistada é Danieli Baldi, doutora em Ciência da Literatura pela UFRJ. Danieli Baldi, que se define, em suas próprias palavras, como "transexual, negra e comunista", é a primeira professora trans a atuar na Escola de Comunicação e Artes da UFRJ, e fala de sua trajetória acadêmica, bem como das trans/ identidades como objeto de estudo emergente na academia brasileira. Finalizando a segunda parte, seguindo a tradição de longa data da $R B L C$, são apresentadas quatro resenhas.

\section{REFERÊNCIAS}

AIZURA, Aren Z. Mobile Subjects: transnational imaginaries of gender reassignment. London: Duke University Press, 2018.

HALBERSTAM, Judith. In a Queer Time and Place: transgender bodies, subcultural lives, New York: New York University Press, 2005.

HINES, Sally. TransForming Gender: transgender practices of identity, intimacy and care. Bristol: The Policy Press, 2007.

STRYKER, Susan. Transgender History: the roots of today's revolution. 2nd. ed. New York: Seal Press, 2017. 